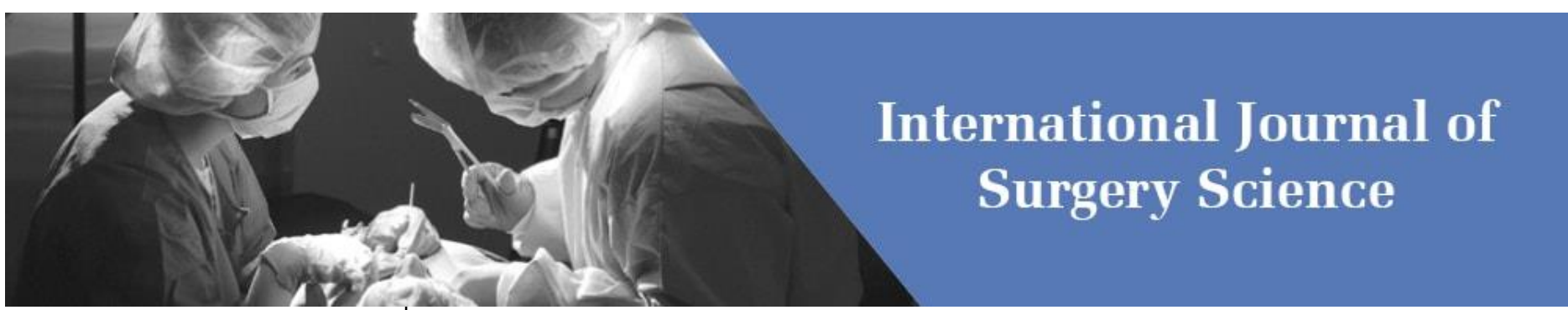

E-ISSN: 2616-3470

P-ISSN: 2616-3462

(C) Surgery Science

www.surgeryscience.com

2021; 5(3): 78-82

Received: 13-05-2021

Accepted: 27-06-2021

Joachim Moba Ndongila

Department of orthopedics and

traumatology, University of

Kinshasa, Kinshasa, Democratic

Republic of Congo

Aliocha Nkodila Natuhoyila

1. Department of Family Medicine and Primary Health Care,

Protestant University in Congo,

Kinshasa, Democratic Republic of Congo

2. Department of Public Health, Lomo University Research,

Kinshasa, Democratic Republic of Congo

Mathieu Loposso Nkumu

Department of Urology, University of Kinshasa, Kinshasa, Democratic

Republic of Congo

Luc Mokassa Bakumo Batan

Department of orthopedics and traumatology, University of

Kinshasa, Kinshasa, Democratic

Republic of Congo

Désiré Mashinda Kulimba

School of Public Health, University of Kinshasa, Kinshasa, Democratic

Republic of Congo

Benjamin Longo Mbenza

1. Department of Public Health, Lomo University Research,

Kinshasa, Democratic Republic of Congo

2. Department of Interna

Medicine, University of

Kinshasa, Kinshasa,

Democratic Republic of Congo

Corresponding Author:

Aliocha Nkodila Natuhoyila

1. Department of Family Medicine and Primary Health Care,

Protestant University in Congo, Kinshasa, Democratic Republic of Congo

2. Department of Public Health, Lomo University Research, Kinshasa, Democratic Republic of Congo

\section{Determinants of fatal road traffic accidents in the democratic republic of Congo from 2011 to 2016}

\author{
Joachim Moba Ndongila, Aliocha Nkodila Natuhoyila, Mathieu Loposso \\ Nkumu, Luc Mokassa Bakumo Batane, Désiré Mashinda Kulimba and \\ Benjamin Longo Mbenza
}

DOI: https://doi.org/10.33545/surgery.2021.v5.i3b.740

\section{Abstract}

Background and purpose: In many low-income countries, the increase in the number of vehicles is likely to have an impact on road traffic fatalities. The purpose of this study was to identify the determinants of fatal road traffic accidents in the Democratic Republic of Congo.

Methods: This was an analytical cross-sectional study on data from road traffic accidents in 6 cities of the DRC over a period from 2011 to 2016, using data from the police stations of these 6 cities. It took into account all accidents on the public road (AVP) that were the subject of a report by police officers. Fatal traffic accident was the dependent variable while socio-demographic characteristics, behavioral and environmental determinants were the independent variables.

Results: In six years, 4,635 accidents have been notified which have caused 945 fatal accidents, an overall frequency of $20.4 \%$. After adjustment in multivariate analysis, the dry season (aOR: 1.66 95\% CI: 1.41 1.96), public transport (aOR: $7.1195 \%$ CI: 5.58-9.05), wrong maneuver (aOR: 2.93 95\% CI: 2.22-3.87), the wrong crossing (aOR: $3.9195 \%$ CI: 2.59-5.92) and drunk driving were (ORa: 4.32 95\% CI: 3.56-5.23) were the independent determinants of fatal accidents.

Conclusion: The fatal accident was linked to human and environmental factors, hence the need for behavior change awareness campaigns.

Keywords: Fatal accidents, determinants, police station, DRC

\section{Introduction}

Modernism, which implies a mechanization of all sectors of the economy and above all a more and more extensive development of road traffic, generates an exponential increase in the number of road traffic accidents, thus posing a major public health problem ${ }^{[1]}$. Data from the World Health Organization (WHO) indicate that in 2019, nearly 1.2 million people died worldwide from road traffic injuries ${ }^{[2]}$. The total annual cost of road traffic accidents for low- and middleincome countries is estimated at US $\$ 65$ billion, which is more than the amount of development aid ${ }^{[3]}$. African countries continue to pay a heavy price for this social scourge. For example, the risk of a fatal accident is higher in Tanzania and Kenya where it is around 60 fatalities per 10,000 vehicles ${ }^{[4]}$. In Côte d'Ivoire, a study carried out by the Road Safety Office (OSER) identified 158,104 traffic accidents over a period of 32 years (from 1970 to 2001), i.e. an average of 4,940 accidents per year, with 10,111 wounded and 593 killed ${ }^{[5]}$. In Kinshasa hospitals, a study carried out in the city of Kinshasa by Moba et al., showed that road traffic accidents are on the rise ${ }^{[6]}$. But this study did not determine the factors associated with fatal traffic accidents in Kinshasa. Thus, it seems opportune to conduct this study, the objective of which was to determine the prevalence of road traffic accidents and to identify the factors associated with fatal road traffic accidents in the DRC.

\section{Materials and methods}

Our study took place in 6 cities in the DRC. These are the city of Kinshasa, Goma, Matadi, Mbandaka, Lubumbashi and Kananga. The data were compiled in these different towns by the military service providing road control. These accident reports came from two sources: the national police for accidents in urban areas and the gendarmerie for accidents in the countryside. Accident reports are drawn up by police officers from the Autonomous District police stations in the various towns, who first register them at the police station before passing them on to the 
police headquarters, which compiled all the data. These accident data are actively collected by police officers on a weekly basis to collect this data in the registers and retrieve the report cards. This was a cross-sectional, analytical study that took place from 2011 to 2016 and focused on road traffic accidents that occurred in the aforementioned 5 cities. The data were obtained from data obtained from the census of all road accidents recorded in various police stations in 6 towns. Prior to analysis, these data were cleared by excluding variables for which there was a lot of missing data (missing PV data). All accidents reported by law enforcement officials were included in the study. The variable of interest studied was the occurrence of a fatal road traffic accident. The explanatory variables were:

- socio-demographic characteristics (sex, age, season);

- the behavioral risk factors of road users (speeding, careless driving, wrong maneuver, bad crossings and drunkenness at the wheel)

- environmental risk factors (time of accident, type of road, condition of the road, category of vehicle, type of accident, accidents involving at least one pedestrian, in built-up areas, in open countryside, accident according to the day of the week, accident according to the type of day, accident according to the month, accident according to the year).

\section{Statistical analysis}

Analyzes were performed on SPSS 21.0. Descriptive statistics consisted of calculating the mean and standard deviation for quantitative data and proportions for categorical data. Pearson's chi-square test or Fisher's exact test was used to compare the proportions, on the other hand Student's t test compared the means. The search for the determinants of fatal accidents was carried out by the logistic regression test in univariate analysis. When differences were observed between the fatal accident and the independent variables, the effect of potential confounders was investigated by logistic regression fitting in multivariate analysis. Finally, the ORs and their 95\% CIs were calculated to determine the degree of association between the fatal accident and the independent variables. The p-value $<0.05$ was considered to be the threshold of statistical significance.

\section{Ethical considerations}

The data was collected anonymously and confidentially. The privacy and personality of the respondents were safeguarded. The three fundamental principles of ethics were respected at the time of the study: the principle of respect for the person, that of beneficence and that of justice.

\section{Results}

\subsection{Overall frequency of accidents}

In six years, 4,635 accidents have been notified which have caused 945 fatal accidents, for an overall frequency of $20.4 \%$ (Figure 1).

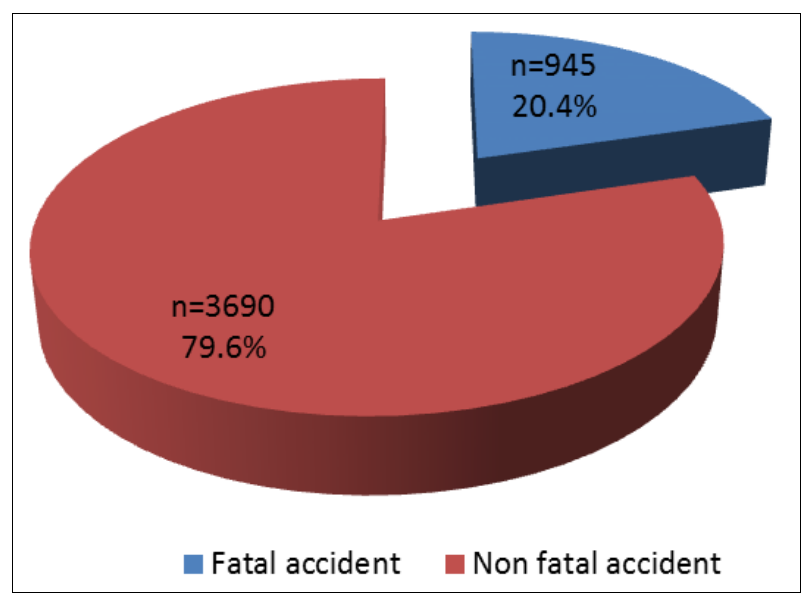

Fig 1: Global frequency of fatal accidents

\subsection{Fatal accident frequencies per year}

The frequency of fatal accidents increased linearly per year but the difference was not statistically significant with a slightly high frequency in 2016 (21.2\%) (Table 1).

Table 1: Frequencies of fatal accidents per year

\begin{tabular}{|c|c|c|c|c|c|}
\hline \multirow{2}{*}{ Year } & \multirow{2}{*}{ Number of accident } & \multicolumn{2}{|c|}{ Non fatal accident } & \multicolumn{2}{c|}{ Fatal accident } \\
\cline { 3 - 6 } & & $\mathrm{n}$ & $\%$ & $\mathrm{n}$ & $\%$ \\
\hline 2011 & 435 & 350 & 80.5 & 85 & 19.5 \\
\hline 2012 & 445 & 360 & 80.9 & 85 & 19.1 \\
\hline 2013 & 755 & 600 & 79.5 & 155 & 20.5 \\
\hline 2014 & 895 & 715 & 79.9 & 180 & 20.1 \\
\hline 2015 & 690 & 550 & 79.7 & 140 & 20.3 \\
\hline 2016 & 1415 & 1115 & 78.8 & 300 & 21.2 \\
\hline
\end{tabular}

\subsection{Frequency of fatal accidents by age}

The distribution of fatal accidents was evenly distributed with a high frequency among passengers over 60 (23.4\%) (Figure 2).

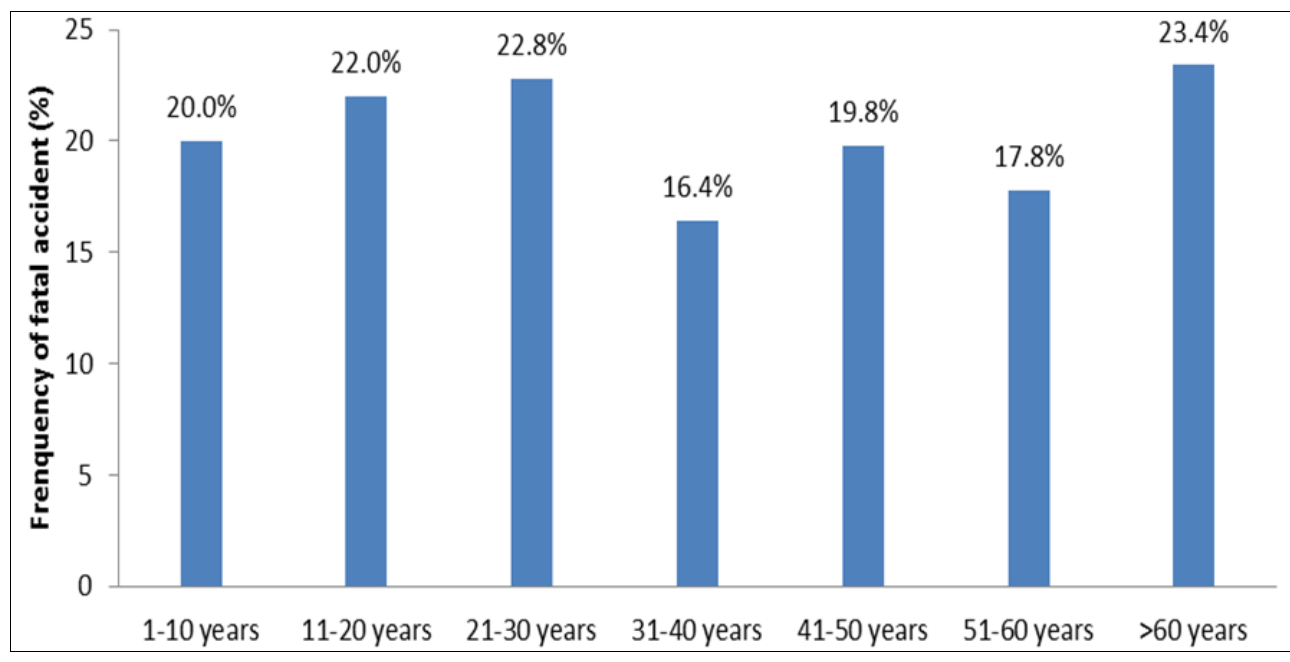

Fig 2: Frenquency of fatal accident $(\%)$ 


\subsection{Frequency of fatal accidents by sex}

Figure 3 indicates that women had significantly more fatal accidents than men $(22.5 \%$ vs. $18.5 \%, \mathrm{p}=0.001)$ (Figure 3$)$.

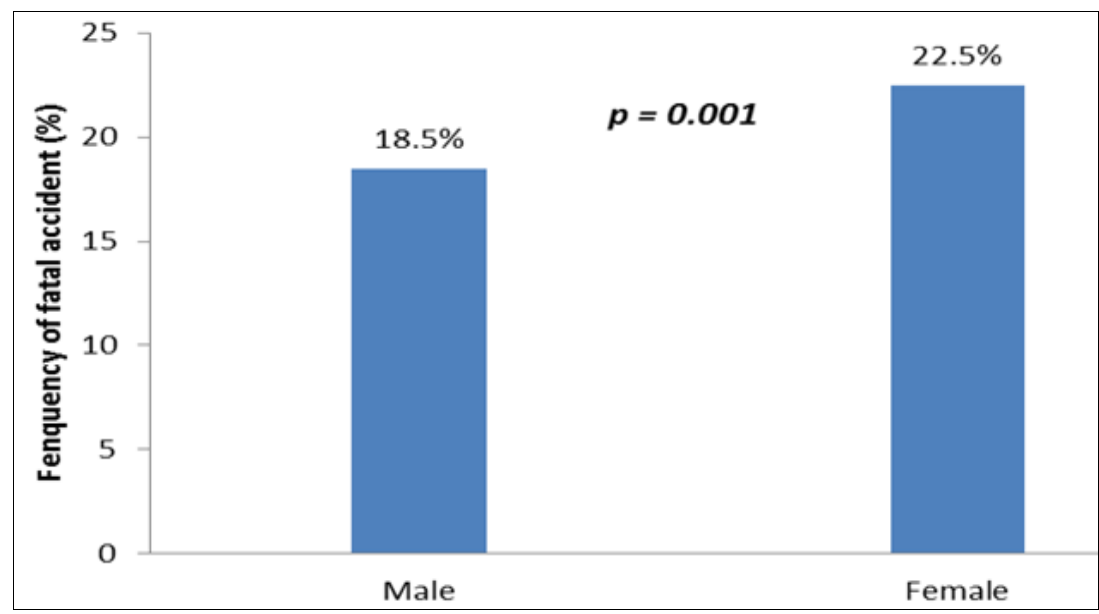

Fig 3: Distribution of fatal accidents by sex

\subsection{Factors favoring accidents}

From the table of factors favoring fatal accidents, this table indicates that women were significantly more exposed to fatal accidents $(\mathrm{p}=0.001)$. In addition, the factors significantly favoring fatal accidents were the dry season, public transport, speeding, careless driving, wrong maneuver, bad crossing and drunk driving $(p<0.05)$ (table 2$)$

Table 2: Breakdown of fatal accidents

\begin{tabular}{|c|c|c|c|}
\hline Variables & Non fatal accident $n=3690$ & Fatal accident $n=945$ & $\mathbf{p}$ \\
\hline Age & $34.1 \pm 15.7$ & $33.6 \pm 16.8$ & 0.200 \\
\hline $1-20$ years & $775(21.0)$ & $215(22.8)$ & \\
\hline $21-40$ years & $1745(47.3)$ & $440(46.6)$ & \\
\hline $40-60$ years & $925(25.1)$ & $215(22.8)$ & \\
\hline$>60$ years & $245(6.6)$ & $75(7.9)$ & \\
\hline Gender & & & 0.001 \\
\hline Male & $2020(54.7)$ & $460(48.7)$ & \\
\hline Female & $1670(45.3)$ & $485(51.3)$ & \\
\hline Season & & & $<0.001$ \\
\hline Rain & $249(67.5)$ & $465(49.2)$ & \\
\hline Dried & $1200(32.5)$ & $480(50.8)$ & \\
\hline Time of accident & & & 0.097 \\
\hline 6-18 hours & $1710(46.3)$ & $415(43.9)$ & \\
\hline 18-6 hours & $1980(53.7)$ & $530(56.1)$ & \\
\hline Type of transport & & & $<0.001$ \\
\hline Public transport & 1730(46.9) & $765(81.0)$ & \\
\hline Motorbike & $760(20.6)$ & $60(6.3)$ & \\
\hline Personal vehicle & $1200(32.5)$ & $120(12.7)$ & \\
\hline Speeding & $1860(50.4)$ & $530(56.1)$ & 0.001 \\
\hline Careless driving & $1670(45.3)$ & $355(37.6)$ & $<0.001$ \\
\hline Wrong growth & $285(7.7)$ & $115(12.2)$ & $<0.001$ \\
\hline wrong crossing & $55(1.5)$ & $60(6.3)$ & $<0.001$ \\
\hline Drunk driving & $575(15.6)$ & $355(37.6)$ & $<0.001$ \\
\hline
\end{tabular}

\subsection{Determinants of fatal accidents}

In univariate analysis, the dry season, public transport, speeding, wrong maneuver, bad crossing and drunk driving were the determinants of fatal accidents. After adjustment in multivariate analysis, the dry season (ORa: 1.66 95\% CI: 1.41-1.96), public transport (ORa: 7.11 95\% CI: 5.58-9.05), wrong maneuver (ORa: 2.93 95\% CI: 2.22-3.87), the wrong crossing (ORa: 3.91 95\% CI: 2.59-5.92) and drunk driving were (ORa: 4.32 95\% CI: 3.56-5.23) were the independent determinants of fatal accidents.

Table 3: Determinants of fatal accidents in logistic regression analysis

\begin{tabular}{|c|c|c|c|c|}
\hline \multirow{2}{*}{ Variables } & \multicolumn{2}{|c|}{ Univariate analysis } & \multicolumn{2}{c|}{ Multivariate analysis } \\
\cline { 2 - 5 } & $\mathbf{p}$ & OR $(\mathbf{9 5 \%} \mathbf{C I})$ & $\mathbf{p}$ & aOR (95\% CI) \\
\hline \multicolumn{5}{|c|}{ Season } \\
\hline Rain & & 1 & & 1 \\
\hline Dried & 0.000 & $2.14(1.85-2.47)$ & $<0.001$ & $1.66(1.41-1.96)$ \\
\hline
\end{tabular}




\begin{tabular}{|c|c|c|c|c|}
\hline \multicolumn{5}{|c|}{ Type of transport } \\
\hline Motorbike & & 1 & & 1 \\
\hline Public transport & 0.000 & $4.42(3.60-5.43)$ & $<0.001$ & $7.11(5.58-9.05)$ \\
\hline Personal vehicle & 0.151 & $0.79(0.57-1.09)$ & 0.423 & $1.17(0.80-1.71)$ \\
\hline \multicolumn{5}{|c|}{ Speeding } \\
\hline No & & 1 & & 1 \\
\hline Yes & 0.002 & $1.26(1.09-1.45)$ & 0.073 & $1.18(0.98-1.41)$ \\
\hline \multicolumn{5}{|c|}{ Wrong growth } \\
\hline No & & 1 & & 1 \\
\hline Yes & 0.000 & $1.66(1.32-2.08)$ & $<0.001$ & $2.93(2.22-3.87)$ \\
\hline \multicolumn{5}{|c|}{ Wrong crossing } \\
\hline No & & 1 & & 1 \\
\hline Yes & 0.000 & $4.48(3.09-6.51)$ & $<0.001$ & $3.91(2.59-5.92)$ \\
\hline \multicolumn{5}{|c|}{ Drunk driving } \\
\hline No & & 1 & & 1 \\
\hline Yes & 0.000 & $3.26(2.78-3.82)$ & $<0.001$ & $4.32(3.56-5.23)$ \\
\hline
\end{tabular}

\section{Discussion}

This study showed that the frequency of fatal traffic accidents was $20.4 \%$ in the 6 cities during the 6 years. This result is different from those of studies conducted by Moshiro in Tanzania (5.98\%) ${ }^{[7]}$, Labinjo in Nigeria (41\%) ${ }^{[8]}$ and Kobusingye in Uganda (38.9\%) ${ }^{[9]}$. Road traffic fatalities were close to the rate reported by Peden in Africa (28.3\%) which was one of the highest in the world ${ }^{[10]}$. This shows the scale and severity of accidents affecting the most active population, resulting in heavy losses for the families of the victims and the states. In the absence of death, these accidents can lead to permanent disability-type sequelae, with loss of productivity as demonstrated in the study by Juillard et al. in Nigeria, which showed that $13.5 \%$ of the injured were unable to return to work [11]. The subjects involved in fatal traffic accidents are $22.5 \%$ females vs. $18.5 \%$ males. This female predominance was also observed by Coulibaly in Mali and Wu in China with 75 and $76.6 \%{ }^{[12,13]}$ as well as Privat and Rougier in France with respectively $83.3 \%$ and $88 \%[14,15]$. This could be explained in part by the fact that the women on the journey are reckless and distracted to save themselves in the event of accidents. Moreover, more than half of fatal traffic accidents occurred between 6 p.m. and 6 a.m. despite the insignificant difference. This period coincides with the end of work time (rush hour) so that it causes traffic jams favoring the occurrence of traffic accidents and more after $10 \mathrm{pm}$ the roads are open causing a speeding of the road. Share of drivers. This could be justified on the one hand, by driver fatigue due to the weight of the work performed during the day with a reduced level of vigilance and sometimes disturbed by drowsiness; on the other hand, poor visibility in the event of insufficient or no public lighting, defective or damaged vehicle lights. This result is comparable to those found in Kenya, Ghana and England [9, 16, 17]. After adjustment in multivariate analysis, the dry season (ORa: 1.66 95\% CI: 1.41-1.96), public transport (ORa: 7.11 95\% CI: 5.589.05), wrong maneuver (ORa: 2.93 95\% CI: 2.22-3.87), the wrong crossing (ORa: 3.91 95\% CI: 2.59-5.92) and drunk driving were (ORa: 4.32 95\% CI: 3.56-5.23) were the independent determinants of fatal accidents. This trend has been confirmed by the work of Madani in Algeria and Afukaar in Ghana ${ }^{[18,19]}$. Our results also corroborate those of Odero in Kenya which showed that the human factor was responsible for the causes of fatal road accidents ${ }^{[20]}$. In Pakistan, the majority of crashes occurred on asphalt roads where drivers tend to speed excessively, causing human and material damage ${ }^{[21]}$.

\section{Limitations of the study}

Despite its local nature, facilitating access to data, this study has some limitations. Bias in the reporting of accident data due to the refusal of a finding by certain users (amicable finding) or the unavailability of the agents responsible for the findings which meant that certain aspects were not addressed.

\section{Conclusion}

The intensification of road traffic in the DRC over the past six years has resulted in an exponential increase in the number of fatal accidents. This documentary study, which consisted of a census of road accidents over a period of six years, showed that, on the one hand, fatal accidents occurred more between 6 p.m. and 6 a.m. The human factor, through non-compliance with the Highway Code (season, speeding, drunkenness and dangerous overtaking) was incriminated in the occurrence of fatal accidents. Faced with these results, the State must take measures aimed at reducing traffic accidents through the adoption and application of laws taking into account the risk factors and carry out user awareness campaigns through various media. Communication. In addition, it is necessary to strengthen the control of the application of the Highway Code by setting up a camera surveillance system on the road networks and the installation of speeding control radars, and to strengthen training in driving schools with the involvement of specialists in psychology.

\section{Conflict of Interest}

The authors declare no conflict of interest

\section{Acknowledgements}

We thank all who participated in the study.

\section{References}

1. Yao GHA, Douba A, Bamba L, Aka LBN, Dagnan NS. Problématique des accidents de la route dans le monde: causes, ampleur et prévention. Abidjan: Afrique Biomédicale 2013;18(1):90-100.

2. Organisation mondiale de la santé (OMS). Rapport mondial sur la prévention des traumatismes dus aux accidents de la circulation. Génève: OMS 2004.

3. Jacobs G, Aeron-Thomas A, Astrop A. Estimating Global Road Fatalities. Transport Research Laboratory 2000, 445.

4. Terje A. La sécurité routière en Afrique: évaluation des initiatives de sécurité routière dans cinq pays africains 1998 , $1-55$.

5. Roux C, Dick R, Dieth A. Morbidité et mortalité de 1894 accidents de la voie publique chez l'enfant au CHU de Yopougon à Abidjan; Médecine d'Afrique Noire 2001, 114. 
6. Moba JN, Mokassa LB, Mashinda DK. Accidents du trafic routier à Kinshasa: profil épidémiologique et prise en charge. Ann. Afr. Med 2016;9(4):2422-2428

7. Moshiro C, Heuch I, Astrom AN et al. Injury morbidity in an urban and a rural area in Tanzania: an epidemiological survey. BMC Public Health 2005;5:11. Doi: 10.1186/14712458-5-11.

8. Labinjo M, Juillard C, Kobusingye OC, Hyder AA. The burden of road traffic injuries in Nigeria: results of a population-based survey. Injury Prevention 2009;15:157-62.

9. Kobusingye O, Guwatudde D, Lett R. Injury patterns in rural and urban Uganda. Inj Prev 2001;7:46-5.

10. Peden M, Scurfield R, Sleet D et al. World report on road traffic injury prevention. Geneva: World Health Organization (WHO) 2004.

11. Juillard C, Labinjo M, Kobusingye O, Hyder AA. Socioeconomic impact of road traffic injuries in West Africa: exploratory data from Nigeria. Injury Prevention 2010;16:389e392. Doi: 10.1136/ ip.2009.025825.

12. Coulibaly Y, MP E, Diallo A et al. Le Traumatisme crânien à L'hôpital du Point G: À propos de 80 cas. Mali Méd 2004;19:3-4.

13. Wu X, Hu J, Zhuo L et al. Epidemiology of traumatic brain injury in eastern China, 2004: a prospective large case study. J Trauma 2008;64(5):1313-9.

14. Privat JM, Marty Double C et al. Étude anatomo-clinique du syndrome du traumatisme crânien grave. Rev EEG Neurophysiol 1979;9:109-15.

15. Rougier A, Bonnaud E, Bastel JP et al. Contrôle anatomique de 30 cas de comas traumatiques graves d'emblée. Rev EEG Neurophysiol 1979;9:101-8.

16. Ghaffar A, Hyder AA, Bishai D. Newspaper reports as a source for injury data in developing countries. Health Policy Plan 2001;16:322-5.

17. Clarke DD, Ward P, Bartle C, Truman W. Killer crashes: fatal road accidents in the UK. Accid Anal Prev 2010;42(2):764-70.

18. Madani A, Tello G. Les principales causes des accidents de la circulation routière et les mesures d'atténuation en Algérie. European Scientific Journal 2015, 11(20). ISSN: 1857 - 7881 (Print) e - ISSN 1857-7431.

19. Afukaar FK. Speed control in developing countries: issues, challenges and opportunities in reducing road traffic injuries. Inj Control Saf Promot 2003;10(1-2):77-81.

20. Odero W, Khayesi M, Heda PM. Road traffic injuries in Kenya: magnitude, causes and status of intervention. Inj Control Saf Promot 2003;10(1-2):53-61.

21. Banque mondiale et Commission économique pour l'Afrique. La sécurité routière en Afrique. Évaluation des initiatives de sécurité routière dans cinq pays africains 1998. 